\title{
The Effect of Two Different Take Offs on Split Leap and Stag Leap with Ring Parameters in Rhythmic Gymnastics
}

\author{
Sezen Çimen Polat ${ }^{1}$ \\ ${ }^{1}$ Gazi University, Abant Sok. No: 12, Yenimahalle, 06330 Ankara, TURKEY \\ *Corresponding Author: sezencimen@gazi.edu.tr \\ Citation: Çimen Polat, S. (2018). The Effect of Two Different Take Offs on Split Leap and Stag Leap with \\ Ring Parameters in Rhythmic Gymnastics. Pedagogical Research, 3(4), 13. https://doi.org/10.20897/pr/3905
}

Published: November 28, 2018

\begin{abstract}
This study was conducted to examine and compare the parameters of leaps executed with two different take offs in rhythmic gymnastics. 15 rhythmic gymnasts competing in novice category (age: 7.6 \pm 0.7 years old; training age: $2.3 \pm 1.2$ years; height: $120.4 \pm 2.4 \mathrm{~cm}$; weight: $20.45 \pm 0.9 \mathrm{~kg}$ ) participated in the study. The selection of the elements of split leap and stag leap with ring was based on 'Rules of Procedure on Rhythmic Gymnastics'. The leaps were first executed with take off from one foot and then with take off from two feet. Gyko Inertial System (Microgate, Bolzano, Italy) and Optojump (Microgate, Bolzano, Italy) measurement tool were used to assess $t$ flight, height, mean distance, velocity and total power of the leaps. SPSS 23 package program was used for the statistical analysis of data. Shapiro-Wilk test was performed to find out whether the data showed normal distribution while Mann-Whitney $U$ test was performed to compare the groups. Statistical level of significance was accepted as $\mathrm{p}<0.05$. The analysis indicated that $\mathrm{t}$ flight, height, velocity and total power results for the split leap performed with take off from 1 foot were significantly higher than the split leap performed with take off from 2 feet $(p<0.05)$. As for stag leap with ring, a significant difference was observed in time of flight (t-flight) and velocity values of the leap executed with the two different take offs $(\mathrm{p}<0.05)$. At the end of the study, it was found that while performing split leap and stag leap with ring elements, gymnasts displayed a better performance with take off from single foot compared to take off from both feet. In light of these results, it is suggested to encourage rhythmic gymnasts in novice category perform technical training with take off from 1 foot during groundwork training.
\end{abstract}

Keywords: rhythmic gymnastics, leap, training

\section{INTRODUCTION}

Rhythmic gymnastics is defined as a high leap demanding sport. Leaping ability is a basic component of rhythmic gymnastics, expected to execute both leap difficulties and choreographic elements (Di Cagno et al., 2008). This ability affects scoring in terms of height and reproducibility. Leaping is a significant component in many sports branches including rhythmic gymnastics. Hutchinson et al. (1998) state that various sport branches have a high, medium or low relationship with leaps, and identify rhythmic gymnastics among high leap demanding sports. Leap is an action that an individual performs against their own weight. Leaping degree depends on diverse elements such as muscular strength, explosive power, body build and proportion, muscular speed, elasticity and motor coordination (Çimen, 2012). Research conducted in Canada and Greece indicates that $80 \%$ of leaping ability is genetic while $20 \%$ can be improved with normal growth and development, nutrition and training programs (Çimen, 2012). In addition to leaping ability, success in rhythmic gymnastics requires a high level of speed, strength, endurance, agility, flexibility, balance and power parameters, therefore rhythmic gymnastics is a multifaceted sport 


Take off for

Figure 1. Two leaps executed with two different techniques

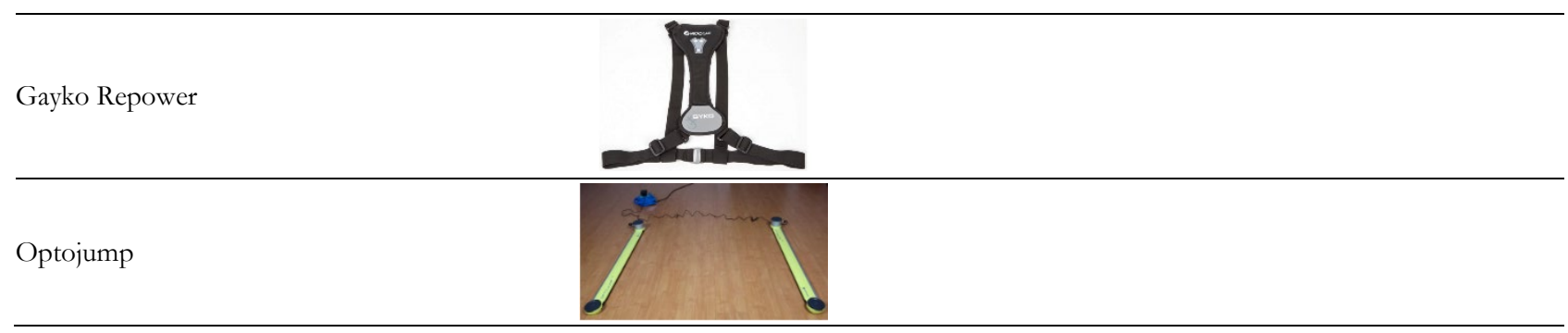

Figure 2. Gyko Repower and Optojump Measurement Tools (Gyko Repower, User Manual, 2018; Optojump Next User Manual, 2018)

(Sleeper et al., 2012). It can be assumed that several factors like technical skills and diverse physiological factors can influence a gymnast's performance (Di Cagno et al., 2008). In rhythmic gymnastics that athletes achieve high performance at early ages compared to other sports, it is of great importance to develop appropriate movement patterns in childhood period. Execution of the correct technique is both an element that will bring success as well as a prerequisite for developing the technique (Donti et al., 2016). In rhythmic gymnastics, a leap consists of three main phases: take off, flight and landing. Take off phase is important in terms of forward and upward direction. Take off can be performed with single foot or two feet as well as in stable position or as advances (Altay and Doğan, 1996). Flight phase determines the character of the leap. The shape the body takes during the flight is important. It is important for judge's assessment. The execution of movements with the right technique by the athlete in terms of competition performance is the most significant element affecting the score. In rhythmic gymnastics, the key criterion for the eligibility of leaping elements in choreography during competition is reaching an accurate and fixed shape (Di Cagno et al., 2010). In a leap without sufficient height, it is also impossible to reach the desired shape. Flight time is important in terms of reaching a fixed shape. Leaps in rhythmic gymnastics are accepted as one of the main body elements that need to be executed as part of choreography (Code of Points, 2017-2020). According to the rules set by the technical board for novice category comprising the study group, it was compulsory to execute either a split leap or stag leap with ring in series. The leaps can be performed preferably with take off from one foot or take off from two feet according to the selected elements or choreography. Considering that these two leaps are the most preferred body elements by athletes in novice category, the aim of this study was to analyze and compare parameters in split leap and stag leap with ring performed after both take offs.

\section{MATERIAL AND METHOD}

This study was conducted on 15 rhythmic gymnasts competing in novice category (age: 7.6 \pm 0.7 years old; training age: $2.3 \pm 1.2$ years; height: $120.4 \pm 2.4 \mathrm{~cm}$; weight: $20.45 \pm 0.9 \mathrm{~kg}$ ). Measurements were made after the gymnasts carried out their own warm-up procedure without coach instructions. They were requested to execute both leaps -split leap and stag leap with ring- with two different take offs (Figure 1). The leaps were selected considering the leaps performed in novice category this year according to 'Rules of Procedure on Rhythmic Gymnastics'. The leaps were performed with take off from one foot and take off from two feet, respectively. Fifteen gymnasts performing both leaps with technical competency (defined and fixed shape, height) were included in the study. Data was obtained using Gyko Inertial System (Microgate, Bolzano, Italy) and Optojump (Microgate, Bolzano, Italy) measurement tools (Figure 2). Gyko RePower Measurement Tool: Gyko is a movement measurement device that allows data transmission to a PC in real time via Bluetooth option (Cigrowski et al., 2017). It consists of an elastic band positioned on the back and a device attached to it. Mean distance, velocity and total power values in technical leaps were assessed using Gyko device. Optojump Measurement Tool: MicrogateOptojump measurement device was used to record flight time and height of leaps (Attia et al., 2016). 
Table 1. Comparison of Split Leap values with different take offs

\begin{tabular}{|c|c|c|c|}
\hline Parameters $(n=15)$ & Take off & Mean \pm Standard Deviation & $p$ \\
\hline \multirow{2}{*}{$\mathrm{t}$ flight (sec) } & Take off from 2 feet & $0.26 \pm 0.03$ & \multirow{2}{*}{$0.02^{*}$} \\
\hline & Take off from 1 foot & $0.46 \pm 0.09$ & \\
\hline \multirow{2}{*}{ Height $(\mathrm{cm})$} & Take off from 2 feet & $9.61 \pm 1.39$ & \multirow{2}{*}{$0.03 *$} \\
\hline & Take off from 1 foot & $16.7 \pm 2.94$ & \\
\hline \multirow{2}{*}{ Mean Distance } & Take off from 2 feet & $8.45 \pm 0.56$ & \multirow{2}{*}{0.12} \\
\hline & Take off from 1 foot & $7.71 \pm 0.42$ & \\
\hline \multirow{2}{*}{ Velocity $(\mathrm{m} / \mathrm{s})$} & Take off from 2 feet & $86.2 \pm 8.17$ & \multirow{2}{*}{$0.00^{*}$} \\
\hline & Take off from 1 foot & $140.4 \pm 7.74$ & \\
\hline \multirow{2}{*}{ Total Power } & Take off from 2 feet & $136.0 \pm 16.5$ & \multirow{2}{*}{$0.05^{*}$} \\
\hline & Take off from 1 foot & $97.3 \pm 10.7$ & \\
\hline
\end{tabular}

Table 2. Comparison of Stag Leap with Ring values with different take offs

\begin{tabular}{|c|c|c|c|}
\hline Parameters $(n=15)$ & Take off & Mean \pm Standard Deviation & $p$ \\
\hline \multirow{2}{*}{ t flight (sec) } & Take off from 2 feet & $0.39 \pm 0.02$ & \multirow{2}{*}{$0.03^{*}$} \\
\hline & Take off from 1 foot & $0.34 \pm 0.52$ & \\
\hline \multirow{2}{*}{ Height $(\mathrm{cm})$} & Take off from 2 feet & $16.7 \pm 0.94$ & \multirow{2}{*}{0.69} \\
\hline & Take off from 1 foot & $15.9 \pm 1.36$ & \\
\hline \multirow{2}{*}{ Mean Distance } & Take off from 2 feet & $7.17 \pm 0.58$ & \multirow{2}{*}{0.35} \\
\hline & Take off from 1 foot & $7.65 \pm 0.61$ & \\
\hline \multirow{2}{*}{ Velocity (m/s) } & Take off from 2 feet & $89.4 \pm 7.03$ & \multirow{2}{*}{$0.02^{*}$} \\
\hline & Take off from 1 foot & $127.7 \pm 10.8$ & \\
\hline \multirow{2}{*}{ Total Power } & Take off from 2 feet & $95.4 \pm 15.2$ & \multirow{2}{*}{0.92} \\
\hline & Take off from 1 foot & $97.2 \pm 16.2$ & \\
\hline
\end{tabular}

As part of statistical analysis, SPSS 23 package program was used for the analysis of data. Shapiro-Wilk test was performed to determine whether the data showed normal distribution, and Mann-Whitney U test was performed to compare the groups. Statistical level of significance was accepted as $\mathrm{p}<0.05$.

\section{DISCUSSION AND CONCLUSION}

At the end of statistical analysis, it was found that take offs from single foot increased flight time, height and velocity in both leaps. However, it was also found that power diminished in the split leap with take off from 1 foot compared to take off from 2 feet. It can be claimed that the reason for this was that split leap was performed with take off from 1 foot technically and other leg was stretched to form a 180 degree angle. In the split leap with take off from 2 feet, both legs were simultaneously stretched with explosive power to reach the required angle. It can be considered that the loss of power in the split leap with take off from single foot may have resulted from it. Studies in different branches demonstrate that leaping ability is affected by power parameter. It is stated that explosive leg power in gymnasts increases leap height (Çimen, 2012), leg power has a statistically significant impact on vertical jump distance in elite handball players (Yldırım and Özdemir, 2010) and there is a significant correlation between isokinetic knee strength and vertical jump height in volleyball players (Nalçakan, 2001). In addition, it is also claimed that flexibility positively affects vertical jump performance in volleyball and handball players (Çon et al., 2012), (Ylldırım and Özdemir, 2010) and there is a strong correlation between sprint speed and vertical jump performance in football players (Ek et al., 2007). In literature review, we found no study analyzing rhythmic gymnastics elements in relation to leaping ability. Only Di Cagno et al. conducted a study in 2008 to determine which parameters are useful indicators of talent identification in rhythmic gymnastics. In the study, they came to the conclusion that level of muscle compliance evaluated by hopping test is a good parameter for athlete selection and leap training. In rhythmic gymnastics, leaps are accepted as one of the main body elements that must be performed in series according to the rules set by Fédération Internationale de Gymnastique. In this context, several leap types are included in the 'code of points' with their scores (Code of Points, 2017-2020). Athletes must execute one or several of these elements according to their age group, level and ability. In rhythmic gymnastics, the key criterion for the eligibility of leaping elements is performing the movement by reaching an accurate and fixed shape (Di Cagno et al., 2010). It is not possible to reach a well-defined shape in a leap without sufficient height. Flight time is important in terms of reaching a fixed shape. The results of this study revealed that children in this age group got higher scores in the leaps with take off from one foot. Although judges evaluate athletes qualitatively during series, quantitative measurements in this study indicated that power, flight time and speed increased in the leaps in this age group when executed with take off from single foot. A study by Hutchinson et al. (1998) to improve leaps in rhythmic gymnasts demonstrated that gymnasts could improve their leaping ability considerably thanks to heavy leaping training. The study tried to draw attention to the relationship between leaping ability and displaying technical skills. When the results of the analysis were assessed, it was seen that particularly leap height 
and flight time can be important criteria in terms of achieving technical competency. In the analysis of the execution of split leap and stag leap with ring, technical leaps performed in this age group according to national rules, with two different take offs, it was observed that take off from one foot resulted in a higher leaping performance than take off from two feet. In light of these results, it is recommended to trainers to get rhythmic gymnasts in novice category perform leaps with take off from 1 foot during groundwork training. It can change in high level athletes and advanced ages considering that strength development could reach higher levels.

\section{REFERENCES}

Altay, F. and Doğan, F. (1996). SportifRitmik Cimnastik, Ankara.

Attia, A., Dhahbi, W., Chaouachi, A., Padulo, J., Wong, D. P. and Chamari, K. (2017). Measurement Errors When Estimating the Vertical Jump Height with Flight Time Using Photocell Devices: The Example of Optojump. Biology of Sports, 34(1), 63-70. https:// doi.org/10.5114/biolsport.2017.63735

Code of Points. (2017-2020). International Gymnastics Federation.

Cigrovski, V., Franjko. I., Rupcic, T., Bakovic, M. and Matkovic, A. (2017). Comparison of Standart and Newer Balance Tests in Recreational Alpine Skiers and Ski Novices. Montenegrin Journal of Sports Science and Medicine, 6(1), 49-55.

Çimen, S. (2012). Farklı Ritmik Cimnastik Branşlarındaki 9-12 Yaş Grubu Kız Sporcuların Antropometrik Özellikleri ve Sıçrama Becerilerinin İncelenmesi. (Master Thesis). Gaz̧i University Institute of Health Sciences, Ankara.

Çon, M., Akyol, P., Tural, E. and Taşmektepligil, M. Y. (2012). The Effect of Flexibility and Body Fat Percentage on Vertical Jump Performance with Volleyball Players. Selcuk. University Journal of Physical Education and Sport Science, 14(2), 202-207.

Di Cagno, A., Baldari, C., Battaglia, C., Gallotta, M. C., Videira, M., Piazza, M. and Guidetti, L. (2010). Preexercise Static Streching Effect on Leaping Performance in Elite Rhythmic Gymnasts. Journal of Strength and Conditioning Research, 24(8), 1995-2000. https:// doi.org/10.1519/JSC.0b013e3181e34811

Donti, O., Bogdanis, G. C., Kritikou, M., Donti, A. and Theodorakou, K. (2016). The Relative Contribution of Physical Fitness to the Technical Execution Score in Youth Rhythmic Gymnastics. Journal of Human Kinetics, 51(1), 143-152. https:// doi.org/10.1515/hukin-2015-0183

Ek, R. O., Temoçin, S., Tekin, T. A. and Yıldız, Y. (2007). Investigation of Interactions Among Some Motor Exercises Applied to Football Players. Journal of Adnan Menderes University Medical Faculty, 8(1), $19-22$.

GykoRepower User Manual. (2018). Available at: https://www.hpcosmos.com/sites/default/files/uploads/documents/manual-en.pdf

Hutchinson, M., Tremain, L., Christiansen, J. and Beitzel, J. (1998). Improving Leaping Ability in Elite Rhythmic Gymnasts. Medicine and Science in Sports and Exercise, 30(10), 1543-1547. https://doi.org/10.1097/00005768199810000-00012

Nalçakan, G. R. (2001). Voleybolcuların İzokinetik Kas Kuvvetleri İle Dikey Sıçrama Yükseklikleri Arasındaki İlişki Düzeyi. (Master Thesis). Ege University Institute of Health Sciences, İzmir.

Optojump Next User Manual. (2018). Available at: http://www.optojump.com/optojumpnext/media/manuals/manual-en.pdf

Sleeper, M. D., Kenyon, L. K. and Casey, E. (2012). Measurnng Fitness in Female Gymnasts: The Gymnastics Functional Measurement Tool. International Journal of Sports Physical Therapy, 7(2), 124-138.

Yıldırım, İ. and Özdemir, V. (2010). The Effects of Anthropometric Measures of Elite Male Handball Team Players on the Vertical and Horizontal Jump Distance. Selçuk. University Journal of Physical Education and Sport Science, 12(1), 63-72. 